\title{
Concordance Between the Size of the Sign and the Errors of First and Second Kind to Investigations in Medicine
}

\author{
Luis Alberto Escalona Fernández, Silvia María Pérez Pérez \\ Faculty of Medical Sciences, Holguín University of Medical Sciences, Holgu, Cuba
}

Email address:

luisalbert@infomed.sld.cu (L. A. E. Fernández)

\section{To cite this article:}

Luis Alberto Escalona Fernández, Silvia María Pérez Pérez. Concordance Between the Size of the Sign and the Errors of First and Second Kind to Investigations in Medicine. International Journal of Theoretical and Applied Mathematics. Vol. 7, No. 4, 2021, pp. 68-71.

doi: $10.11648 /$ j.ijtam.20210704.12

Received: June 28, 2021; Accepted: July 13, 2021; Published: August 9, 2021

\begin{abstract}
Background: the relationship between sample size and errors of the first and second type, which are taken in those studies, where there are properly supported hypotheses, who is detailed in the classical literature; but without indicating a design of the methodology to follow. These analytical resources, as well as the ways to obtain the experimental data. Aims: to design a methodology to establish the concordance between the sample size, such as clinical trials, controlled and randomized studies in medicine. Method: statistical methods, procedures, and algorithms are applied, combined with theoretical methods: analysis-synthesis, induction-deduction, and abstraction-concretion to determine the size of the sample. The empirical methods applied are framed mainly in the observation of the records of the experimental data. The document review method is used, through books, and articles referring. Results: a methodology is designed, in which the correspondence between the minimum size of the sample. Conclusions: through elaborated health situations, the need to establish a methodology as a work tool to determine the concordance between the sample size, the errors of the first and second gender is evidenced; in research with a predetermined significance level, based on experimental data in clinical trials, controlled and randomized studies in medicine.
\end{abstract}

Keywords: Mathematical Model, Resolution of Medical Problems, Experimental Design

\section{Introduction}

When developing mixed studies, it is necessary to specify the sample size, the first and second gender errors $\alpha$ and $\beta$, establish a relationship among these to ensure the veracity and reliability of the research, as well as the effectiveness of the results by hypothesis verification and interval estimation, using the working techniques of classical inference statistics. [1-3]

The determination of these elements are not always used adequately, however the foundation of any research that is developed must be supported by these statistical tools and techniques, and work mathematics. [4-6]

For the analysis of the collected data, as well as the verification of the inferred results, from a study sample, they generally depend on an experimental design, where the reliability and efficacy of the study (minimum sample size) is ensured, in which the importance is emphasized, and the correspondence of the deductions, from the study sample to the population it represents. [7-9]
Some authors point out the need to interpret first and second gender errors in research to highlight the results achieved in the research; [10-12] but it is decisive to ensure their veracity and reliability from the beginning, therefore it is essential to specify the minimum size of the sample in such a way as to certify the inquiries obtained. [13-15]

That is, ideas are retaken in depth, which acquire leading dimensions from the initial stages to the final ones, for which the objective is addressed: to design a methodology to establish the concordance between the sample size, the first and second errors gender of experimental data that ensure the reliability and veracity of research such as clinical trials, controlled and randomized studies in medicine. [16-18]

\section{Materials and Methods}

Mathematical and statistical methods, procedures, and algorithms are applied, combined with the theoretical methods: analysis-synthesis, induction-deduction, and abstraction-concretion to determine the minimum size of the 
sample, based on fixing the errors of the first and second gender.

A methodology is designed to ensure the processes of understanding, explanation and interpretation in the analysis of experimental data, [1-3] to guarantee the reliability and veracity of the study.

The empirical methods applied are framed mainly in the observation of the records of the experimental data, the bibliographic review, in order to deepen the problem and obtain information on the main difficulties that affect the research process, and the published reports, from of the search for methods and procedures.

The document review method is used, through books, and articles referring to the topic Inferential Statistics in the Scielo, DOAJ, Latindex, Google Scholar Databases, Elsevier, among others. [10-12]

\section{Results}

The methodology designe concordance between sample size, first and second gender errors, $\alpha$ and $\beta$, to ensure the reliability and veracity of research, such as clinical trials, controlled and randomized studies, is made up of the following steps:

(I) Formulation of the statistical hypothesis.

(II) Determination of the minimum size of the study sample, based on prefixing the errors of the first and second gender $\alpha$ and $\beta$.

(III) Verification of the statistical hypothesis, preset a level of significance (reliability).

(IV) Construction of the confidential interval, which allows comparing the results obtained in the (III) verification of the statistical hypothesis (the veracity of the study is ratified).

(V) Interpretation of the results obtained, which allows to conclude the analysis of the transformation of the initial health situation.

Biomedical problems are elaborated to illustrate the application of the designed methodology.

Problem 1. A population made up of the Elderly belonging to the San Andrés Polyclinic, Holguín, is considered. The average number of beats per minute is 80 , with a standard deviation of 4 beats per minute which are recorded before performing systematic physical exercises. These population averages are considered to be normally distributed. Six months later, 53 older adults are randomly selected, the average heart rate is 78 beats per minute.

1. Make statements $\mathrm{H}_{0}$ and $\mathrm{H}_{1}$. (I)

2. What is the minimum size necessary to verify hypothesis $\mathrm{H} 0$ : beats per minute, and hypothesis $\mathrm{H}_{1}: \mathrm{m}=78$ beats per minute, when the first gender error $\alpha=0.01$; and the second gender $\beta$, do not exceed 0.1 . Indicate the critical domain. (II)

3. Determine the probability of first and second gender errors $\alpha$ and $\beta$ for the critical domain criterion. (II)

Problem 2. Consider valid the conditions of problem 1. Verify hypothesis $\mathrm{H}_{0}$ : beats per minute, as an alternative hypothesis $\mathrm{H}_{1}$ : beats per minute at the significance level $\alpha=0.01$, based on the construction of the confidential interval of the parameter $\mathrm{m}$ (mean, average). (III)

When deepening by means of the documentary review in the reports of studies in different databases, [13-15] no details are made that verify the concordance of aspects related to the experimental design, when continuing search no findings that ratify this gap are found. [16-18] Thus, the aforementioned condition is not ratified from now on. [19]

Problem 3. The data contained in the technical certification of a drug show its effectiveness in $80 \%$ of cases to cure a certain type of dermatitis. As a result of the modifications of the therapy, an increase in its effectiveness is expected. To verify this statement, checks are made, 121 patients are randomly selected, and 108 of them were cured with modifications in the treatment. Suppose that the sample of patients is obtained from a normally distributed mother population whose proportion is $\mathrm{P}=0.80$. Compare the reported results. [1]

1. What is the minimum size necessary to verify the null hypothesis:

$\mathrm{H}_{0}$ : Classical therapy is applied, which does not influence the increase in the effectiveness (proportion) of the drug, and the alternative hypothesis.

$\mathrm{H}_{1}$ : Modified therapy is applied, which influences the increase in the effectiveness of the drug, when the first gender error $\alpha=0.01$; and the second gender error $\beta$, do not exceed 0.1 . Indicate the critical domain.

1. Determine the probability of errors of the first and second gender $\alpha$ and $\beta$ for the critical domain criterion. (II)

2. Consider the conditions of the problem valid. Verify hypothesis H0: Classical therapy is applied, which does not influence the increase in the effectiveness (proportion) of the drug, as well as alternative hypothesis $\mathrm{H}_{1}$ : Modified therapy is applied, which has an influence on increasing effectiveness of the drug at the significance level $\alpha=0.01$, based on the construction of the confidential interval of the parameter $p$ (proportion). (IV)

\section{Discussion}

In solving the problems raised above, it is necessary to delve into the statistical tools and techniques supported by the methods, procedures and ways to stimulate the creative thinking of researchers. [1]

The concordance of the study sample size and the errors of the first and second gender and are not specified in the reviewed research reports. Compare with analyzes presented in the scientific literature. [1-3] Through steps $a$ in the designed methodology.

Problem 1: (I)

1. $\mathrm{H}_{0}: \mu_{0}=80$, the average of the beats per minute of the Older Adult is equal to 80 .

$\mathrm{H}_{1}: \mu_{0}=78$, the average of the beats per minute of the Senior Adult is equal to 78 .

2. Mathematical (statistical) model is represented by the densities of the normal probabilistic distributions of the mean 
(of beats per minute of the Elderly):

$$
\mathrm{N}\left(\mu_{0}=80 ; \sigma=4 / \sqrt{53}\right), \text { y } \mathrm{N}\left(\mu_{0}=78 ; \sigma=4 / \sqrt{53}\right) .
$$

According to the problem data, the following system is considered:

$$
\left\{\begin{array}{l}
P\left[X<x_{k}^{\prime} / H_{0}: m=80\right]=\Phi\left(\frac{\dot{x}_{k}-80}{\sqrt{\frac{16}{n}}}\right)=0.01 \\
P\left[X \dot{x}_{k}^{\prime} / H_{1}: m=78\right]=1-\Phi\left(\frac{\dot{x}_{k}-78}{\sqrt{\frac{16}{n}}}\right) \leq 0.1
\end{array}\right.
$$

Thus, the system is solved by simplifying:

$$
\left\{\begin{array}{l}
\frac{\dot{x}_{k}-80}{4} \sqrt{n}=u_{0.01}=-2,326 \\
\frac{\dot{x}_{k}-78}{4} \sqrt{n} \geq u_{0.9}=1.282
\end{array}\right.
$$

The system is simplified, then $n \geq 53$.

By substituting the minimum value of $n$ in the first equation of the system, the value of the boundary of the critical domain is determined: $\dot{x}_{k}=80-\frac{2 *(2.326)}{\sqrt{53}} \approx 78.72$.

Therefore, the critical domain is defined by inequality $X<78.72$. (II)

3. Substitute $\mathrm{n}=53, \dot{x}_{k}=78.72$, and obtain:

$$
P\left[\dot{X}<x_{k}^{\prime} / H_{0}: m=80\right]=\underset{0.01}{\Phi}\left(\frac{78.72-80}{\sqrt{\frac{16}{53}}}\right) \approx \Phi(-2.329)=
$$

$$
\begin{array}{r}
P\left[Z \in V_{k}\right]=\propto ; V_{k}: \text { CriticalDomain, } P\left[Z \in V \backslash V_{k}\right] \\
=1-\alpha, V \backslash V_{k}: \text { ApprovalDomain. }
\end{array}
$$

This means, according to the accepted criteria $\left(\mathrm{H}_{0}: \mu_{0}=80\right)$, $1 \%$ of the patients are classified as patients with an average of less than 80 beats per minute.

On the condition that the hypothesis $\mathrm{H}_{1}: \mu_{0}=78$ is correct, the statistic has the normal distribution $\mathrm{N}\left(\mu_{0}=78 ; \sigma=4 / \sqrt{53}\right)$.

According to the equation $\beta=P\left[Z \in V \backslash V_{k} / H_{1}\right]$, the probability of the second kind error is equal to:

$$
\begin{gathered}
\beta=P\left[\dot{X} \geq x_{k}^{\prime} / H_{1}: m=78\right]=1-\Phi\left(\frac{78.72-78}{\sqrt{\frac{16}{53}}}\right)=1- \\
\Phi(1.31) \\
1-0.9049=0.0951 \leq 0.1 ;
\end{gathered}
$$

That is: $\beta=P\left[Z \in V \backslash V_{k} / H_{1}\right]=0.0951 \approx 0.1$ (III)

Therefore, according to the acceptance criteria, $10 \%$ of older adult patients are classified with an average of 78 beats per minute, due to the systematic performance of physical exercises for six months. (V)

If the hypothesis is verified $H_{0}: \theta_{1}=\theta_{2}$, the confidential interval for the difference $\theta_{1}-\theta_{2}$ is examined. The hypothesis $\mathrm{H}_{0}$ is accepted for the difference $\theta_{1}-\theta_{2}$ covers the null value (0). Establish analogies with reports made. [1-4]

The exception consists in the verification of the hypothesis about the equality of the variances $H_{0}: \sigma_{1}^{2}=\sigma_{2}^{2}$; since the confidential interval is constructed for the relation of the variables, the hypothesis $\mathrm{H}_{0}$ in this case is accepted, if the interval in question covers the value equal to the Unit.

Problem 2. (IV)

The upper limit (upper bound) $m_{2}$ of the interval to the left is determined, that is $\left(-\infty ; m_{2}\right)$, for the parameter $m$, when the confidential probability of the percentile $Z_{0.99}=2.392$, is obtained:

$$
m_{2}=\dot{x}+Z_{1-\alpha} \frac{\sigma}{\sqrt{n}}=78+(2.329) \frac{4}{\sqrt{53}}=79.3
$$

As the value of the mean $\mathrm{m}=80$ beats per minute of older adults is not covered by the interval, the null hypothesis $\mathrm{H}_{0}$ : $\mu_{0}=80$ must be rejected, which coincides with the result obtained when solving problem 1.

Problem 3. (I, II, III)

1. According to the data, the following system is considered:

$$
\left\{\begin{array}{c}
P\left[\dot{P}>p_{k}^{\prime} / H_{0}: P=0.8\right]=1-\Phi\left(\frac{\dot{p}_{k}-0.8}{\sqrt{(0.8) *(0.2) / n}}\right)=0.01 \\
P\left[\dot{P}^{\prime} \leq p_{k}^{\prime} / H_{1}: p=0.9\right]=\Phi\left(\frac{\dot{p}_{k}-0.9}{\sqrt{(0.8) *(0.2) / n}}\right) \leq 0.1
\end{array}\right.
$$

Thus, the system is solved by simplifying:

$$
\left\{\begin{array}{c}
P\left[\dot{P}^{\prime}>p_{k}^{\prime} / H_{0}: P=0.8\right]=1-\Phi\left(\frac{\dot{p}_{k}-0.8}{\sqrt{(0.8) *(0.2) / n}}\right)=0.01 \\
P\left[\dot{P}^{\prime} \leq p_{k}^{\prime} / H_{1}: p=0.9\right]=\Phi\left(\frac{\dot{p}_{k}-0.9}{\sqrt{(0.8) *(0.2) / n}}\right) \leq 0.1
\end{array}\right.
$$

The system is simplified, then $n \geq 118$.

By substituting the minimum value of $n$ in the first equation of the system, the value of the boundary of the critical domain is determined: $\dot{p}_{k}=0.8+\frac{(0.4) *(2.326)}{\sqrt{118}} \approx$ 0.88565 .

Therefore, the critical domain is defined by the inequality $P<0.88565$.

2. The lower limit (lower bound) is determined for the interval to the right of the proportion, that is $\left(p_{1} ;+\infty\right)$, for the parameter $\mathrm{p}$, when the confidential probability of the percentile $Z_{0.99}=2.392$ is obtained:

$$
p_{1}=\dot{p}-Z_{1-\alpha} \sqrt{\frac{p q}{n}}=0,90-(2.329) \sqrt{\frac{(0.8) * 0.2}{121}}=0.8287
$$

As the value of the proportion $\mathrm{P}=0.8$; when classical therapy is applied in patients, it is not covered by the interval $(0.8287 ;+\infty)$, (IV) the null hypothesis $\mathrm{H}_{0}: \mathrm{P}=0.8$ must be rejected, which coincides with the result when solving the problem by contrasting hypotheses with a right tail. (V)

The use of professional statistical programs is recommended, which ensure data processing with speed, precision, accuracy, and a high level of reliability. Compare with reports made. [1-4] 


\section{Conclusions}

It is necessary that the professionals of the Medical Sciences demonstrate in the analysis of the health situation, the application of the designed methodology, which ensures the reliability and veracity of the study to be developed, according to the steps to follow:

(I) Formulation of the statistical hypothesis.

(II) Determination of the minimum size of the study sample, based on prefixing the errors of the first and second gender $\alpha$ and $\beta$.

(III) Verification of the statistical hypothesis, preset a level of significance (reliability).

(IV) Construction of the confidential interval, which allows comparing the results obtained in the (III) verification of the statistical hypothesis (the veracity of the study is ratified).

(V) Interpretation of the results obtained, which allows to conclude the analysis of the transformation of the initial health situation.

It is recommended to deepen the application of statistical techniques to analyze the information collected, using inferential statistics work tools to model and simulate experimental data with the help of professional statistical programs.

\section{References}

[1] Escalona L A, Pérez S M. Didactic alternative to stimulate the creative thinking of teachers and students. AMC Magazine [Internet]. 2019 [cited 2020 Jun 16]; 23 (1): [approx. 9 p.]. Available at: http://www.revistaamc.sld.cu/index.php/amc/article/view/6113.

[2] De la Horra J. Applied Statistics [Internet]. Madrid, Spain: Editorial Díaz de Santos S. A; 2012 [cited 2018 Mar 28]. Available

https:/estadisticaunicaes.files.wordpress.com/2012/05/unedestadc3adstica-aplicada-julic3a1n-de-la-horra.pdf.

[3] Efímov A, Korakulin P, Pospélov P, Teréschenko A, Vokolov E, Zemskov V, et al. Problems of Higher Mathematics. Moscow: Editorial Mir; 2014.

[4] Koroliuk V. Manual of probability theory and mathematical statistics. Moscow: Editorial Mir; 2016.

[5] Pérez, S. The hypothetical deductive reasoning in the training of the general practitioner. Doctoral thesis, Holguín Higher Pedagogical Institute. Cuba. [cited 2020 September 12]. Available at: http://tesis.sld.cu/index.php?P=Home.

[6] Escalona L A. Construction and interpretation of curves of elementary functions and the resolution of optimization problems to solve medical professional problems. Thesis as an option to the scientific degree of Doctor in Pedagogical Sciences, University of Holguín. Cuba. 2019 [cited 2020 January 10]; [approx. 216p.] Available at: http://tesis.sld.cu/index.php?P=Home.

[7] Swift L, Miles S, Price GM, Shepstone L, Leinster SJ. Do doctors need statistics? Doctors' use of and attitudes to probability and statistics. Stat Med. 2009; 28 (15): 1969-81.
[8] Gambrill, W., "False Positives on Newborns' Disease Tests Worry Parents", Health Day, (5 June 2006).

[9] Who Working Group on the Clinical Characterization and Management of COVID-19 infection. A minimal common outcome measure set for COVID-19 clinical research. Lancet. 2020 [cited 2020 July 23]; Available from: https://www.thelancet.com/journals/laninf/article/PIIS14733099(20)30483-7/fulltext\#\%20.10.1016/S14733099(20)30483-7 [PMC free article] [PubMed].

[10] Ball G. Continuous safety monitoring for randomized controlled clinical trials with blinded treatment information. Part 4: one method. Contemp Clin Trials. 2011; 32 Suppl 1: S11-7. doi: 10.1016/ j.cct.2011.05.008 [PubMed] [CrossRef] [Google Scholar].

[11] Kaiser LD. Dynamic randomization and a randomization model for clinical trials data. Stat Med. 2012; 31 (29): 38583873. doi: 10.1002/ sim.5448 [PMC free article] [PubMed] [CrossRef] [Google Scholar].

[12] Rees EM, Nightingale ES, Jafari Y, Waterlow N, Clifford S, Pearson CAB, et al. COVID-19 length of hospital stay: a systematic review and data synthesis. medRxiv 2020.04.30.20084780; [cited 2020 July 23]. Available from: https://www.medrxiv.org/content/10.1101/2020.04.30.200847 80v3. DOI: 10.1101/2020.04.30.20084780 [PMC free article] [PubMed].

[13] Wang $\mathrm{Y}$, Zhang D, Du G, Du R, Zhao J, Jin Y, et al. Remdesivir in adults with severe COVID-19: a randomised, double-blind, placebo-controlled, multicentre trial. Lancet. 2020; 395: 1569-78. https://doi.org/10.1016/S0140-6736 (20)31022-9.SS

[14] Hung IF, Lung KC, Tso EY, Liu R, Chung TW, Chu MY, et al. Triple combination of interferon beta- $1 \mathrm{~b}$, lopinavirritonavir, and ribavirin in the treatment of patients admitted to hospital with COVID-19: an open-label, randomised, phase 2 trial. Lancet. 2020; 395 (10238): 1695-704. https://doi.org/10.1016/S0140-6736(20)31042-4..

[15] Boulware DR, Pullen MF, Bangdiwala AS, Pastick KA, Lofgren SM, Okafor EC, et al. A randomized trial of hydroxychloroquine as Postexposure prophylaxis for Covid19. N Engl J Med. 2020: NEJMoa2016638. https://doi.org/10.1056/NEJMoa2016638.

[16] Ingram DD, Kleinman JC. Empirical comparisons of proportional hazards and logistic regression models. Stat Med. 1989; 8 (5): 525-38. https://doi.org/10.1002/sim.4780080502.

[17] Aadland, E.; Andersen, L. B.; Anderssen, S. A.; Resaland, G. K.; Kvalheim, O. M. Associations of volumes and patterns of physical activity with metabolic health in children: A multivariate pattern analysis approach. Prev. Med. 2018, 115, 12-18 [CrossRef] [PubMed].

[18] Kaiser LD. Dynamic randomization and a randomization model for clinical trials data. Stat Med. 2012; 31 (29): 3858 73. https://doi.org/10.1002/sim.5448.

[19] Srivastava DK, Rai SN, Pan J. Robustness of an odds-ratio test in a stratified group sequential trial with a binary outcome measure. Biom J. 2007; 49 (3): 351-64. 